\title{
Impact of Mitral Regurgitation on Exercise Capacity and Clinical Outcomes in Patients with Ischemic Left Ventricular Dysfunction
}

Catherine Szymanski, MD ${ }^{\mathrm{a}, \mathrm{b}}$, Robert A. Levine, MDa, Christophe Tribouilloy, MD, PhD ${ }^{\mathrm{b}}$, Hui

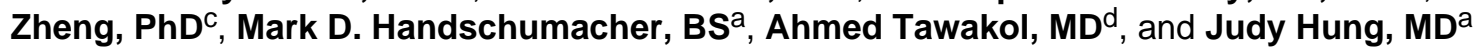

${ }^{a}$ Cardiac Ultrasound Laboratory, Massachusetts General Hospital, Harvard Medical School, Boston, MA, USA

${ }^{b} \mathrm{CHU}$ Amiens Sud, Département de Cardiologie, Avenue René Laënnec, Amiens, France

'Biostatistics Center, Massachusetts General Hospital, Harvard Medical School, Boston, MA, USA

dNuclear Cardiology, Massachusetts General Hospital, Harvard Medical School, Boston, MA, USA

\section{Abstract}

There is uncertainty and debate regarding whether ischemic mitral regurgitation (MR) is a secondary epiphenomenon resulting from left ventricular (LV) dysfunction or confers an independent effect on exercise capacity and outcomes. We tested whether ischemic MR negatively impacts exercise capacity, cardiovascular morbidity and mortality in patients with coronary artery disease (CAD) and inferior wall motion abnormality patients, independent of LV dysfunction. Clinical follow-up over 5 years was obtained in 77 patients (age $64 \pm 10$ years, LVEF $54 \pm 11 \%$ ) with at least mild ischemic MR from CAD and evidence of inferior wall motion abnormality, who had exercise stress testing with perfusion imaging within 24 hours of echocardiography. Patients with active heart failure, ischemia, intrinsic valve disease, pulmonary and vascular disease were excluded. Exercise capacity (METs, peak double product) was tested for relation to MR (vena contracta (VC) and jet area), LV size and function, and pulmonary pressures. Cox proportional hazards analysis assessed whether MR predicted cardiovascular events, including hospitalization for heart failure, acute coronary syndrome, and myocardial infarction, and cardiovascular (CV) and total mortality. Univariate correlation identified MR with both $\mathrm{VC}(\mathrm{r}=-0.674, \mathrm{p}<0.0001)$ and MR jet area $(r=-0.575, p<0.0001)$ as determinants of reduced functional capacity evaluated by METs, with VC the stronger predictor. MR VC $>2 \mathrm{~mm}$ (moderate ischemic MR) and age were independent predictors of $\mathrm{CV}$ events and death (HR 6.72 for $\mathrm{MR}, \mathrm{p}=0.04$ ). In conclusion, in patients with CAD and LV inferior wall motion abnormality, MR impacts negatively on exercise capacity and is associated with increased cardiovascular morbidity and mortality. This effect appears independent of degree of LV dysfunction.

(C) 2011 Excerpta Medica, Inc. All rights reserved.

Address for correspondence: Judy Hung, MD, Massachusetts General Hospital, Cardiac Ultrasound Laboratory, 55 Fruit Street, Blake 256, Boston, MA 02114, Phone: (617) 724-1995, FAX: (617) 726-8383, jhung@ partners.org.

Publisher's Disclaimer: This is a PDF file of an unedited manuscript that has been accepted for publication. As a service to our customers we are providing this early version of the manuscript. The manuscript will undergo copyediting, typesetting, and review of the resulting proof before it is published in its final citable form. Please note that during the production process errors may be discovered which could affect the content, and all legal disclaimers that apply to the journal pertain. 


\section{Keywords}

exercise capacity; ischemic mitral regurgitation

\section{Introduction}

Evaluation of functional capacity by exercise testing is widely used in the diagnosis and functional evaluation of coronary artery disease (CAD) and is a strong predictor of prognosis ${ }^{1-5}$. The direct influence of ischemic MR on exercise capacity, however, is unknown. An independent effect of MR on functional capacity in patients with CAD would strengthen the case for the clinical importance of the lesion and have a significant impact on clinical decision-making, providing a rationale for treating this vexing valvular problem ${ }^{6}$. Therefore the purpose of this study was to test the hypothesis that ischemic MR has an effect on exercise capacity independent of the severity of segmental and global measures of left ventricular (LV) dysfunction, as well as an independent effect on cardiovascular (CV) morbidity and mortality. We examined patients with inferior wall motion abnormalities because this population allows examination of a homogenous group of patients with relatively similar LV function and remodelling characteristics.

\section{Methods}

We reviewed the echocardiographic database from last 5 years for patients with stable CAD with evidence of inferior wall motion abnormality, who had exercise stress testing with perfusion imaging within 24 hours of echocardiography. Patients with inferior wall motion abnormality were selected because, based on the mechanism of ischemic MR, these patients are prone to develop ischemic MR; importantly, therefore, they provide a population that allows testing the relation of MR to exercise capacity in the absence of global LV dysfunction or active heart failure ${ }^{7}$. Patients with active heart failure, ischemia, intrinsic mitral valve disease, significant concomitant aortic valve disease, congenital heart disease, valve prostheses, vegetations, and poor image quality were excluded $(n=5)$. Patients with significant pulmonary disease, peripheral vascular disease and renal failure were also excluded $(n=7)$.

Transthoracic resting echocardiograms were performed according to routine laboratory protocol using either a Vivid 7 system (GE Healthcare, Milwaukee, MI) or a Philips ie33 system (Philips Medical Systems, Andover, MA). Standard 2D parasternal and apical views were obtained using a $2.5-\mathrm{MHz}$ transducer with harmonic imaging for optimal penetration and image quality. Data were recorded in digital format and stored on optical or digital video disks from the apical 2-chamber and 4-chamber views for offline analysis (Philips Medical Systems, Xcelera). All measurements were averaged over at least three cardiac cycles. Echo measurements were made blinded to results of exercise.

End-diastolic (largest dimension of LV cavity at onset of QRS complex) and end-systolic (smallest dimension of LV cavity) LV volumes and ejection fraction (EF) were calculated by the Simpson biplane method of disks from the apical 2-chamber and 4-chamber views according to the recommendations of the American Society of Echocardiography ${ }^{8}$. LV enddiastolic and end-systolic diameters (LVEDD and LVESD) were assessed from parasternal long axis-views. LV global remodeling was quantified by the calculation of LV sphericity index as the ratio of end-diastolic left ventricular major axis over minor axis in the apical 4chamber view, as previously described ${ }^{9}$. Left atrial (LA) volume was measured by the biplane area-length method ${ }^{10}$. Right Ventricular Systolic Pressure (RVSP) was estimated 
from the systolic transtricuspid pressure gradient (in $\mathrm{mmHg}$ ), using the simplified Bernoulli equation $\left(\Delta \mathrm{P}=4 \mathrm{~V}^{2}\right.$, with $\mathrm{V}=$ maximal tricuspid regurgitant velocity in $\left.\mathrm{m} / \mathrm{sec}\right)$.

Diastolic function was evaluated from the mitral inflow recorded at the mitral leaflet tips. Ewave (early diastolic flow), A-wave (late diastolic flow), E-wave deceleration time, and E/A velocity ratio were measured. Peak early diastolic mitral annular velocities were obtained by pulse-wave tissue Doppler imaging from the apical four-chamber view using both the septal and the lateral sites. The averaged $\mathrm{e}^{\prime}$ was used to calculate the ratio of peak early-diastolic transmitral flow velocity $\mathrm{E}$ to $\mathrm{e}^{\prime}$ in order to estimate LV filling pressures ${ }^{11,12}$.

The LV outflow tract stroke volume was calculated by multiplying the LV outflow tract area by the LV outflow tract velocity - time integral measured by pulsed-wave Doppler and LV outflow tract diameter measured in parasternal long axis-view with a zoom on the aorta.

Quantification of MR was performed by vena contracta width, a central and direct measure of the jet emerging from the regurgitant orifice, which was measured from the apical longaxis view ${ }^{13}$ (figure 1). The color flow imaging frame rate was maximized by selecting the narrowest sector angle, and regional image expansion was used to maximize its visualization. The largest vena contracta diameter was averaged over three cardiac cycles ${ }^{14}$. As a correlative method, we also used regurgitant color jet area / left atrial area ${ }^{15-17}$, a measure that is well - suited to the central (non-eccentric) jets of ischemic MR. Left atrial area and regurgitant jet area were measured by planimetry from the apical 4-chamber and 2chamber views and then averaged to calculate their ratio. The valvular tenting area enclosed between the annular line and the mitral leaflets was obtained from the apical 4-chamber view in midsystole.

LV regional contractility was scored using three short-axis views. The LV was divided into 20 standard segments and a score was allocated to each segment according to its contractility as (0) normokinetic, $(+1)$ hypokinetic, $(+2)$ akinetic, or $(+3)$ dyskinetic. A global wall motion score was calculated by summating these values, and the wall motion score (WMS) index was obtained by dividing WMS by the number of scored segments ${ }^{18}$. The 20-segment model is one of a number at wall motion score models proposed and is one that has been used at our institution for more than 25 years. The advantage of a 20 -segment model is a more precise mapping of apical function. Furthermore, consistency in the type of model is more important than the actual wall motion model employed.

Exercise testing with sestamibi single photo emission computed tomography (mibi SPECT) for detecting ischemia was performed within 24 hours of echocardiography. Beta-adrenergic blocking agents were stopped 24 hours before the test. Symptom-limited treadmill exercise was performed using the Bruce protocol. Electrocardiograms were continuously monitored during exercise and for an additional $5 \mathrm{~min}$ in recovery. Blood pressures were continuously taken during the last $30 \mathrm{~s}$ of each exercise stage then each minute during the $5 \mathrm{~min}$ of recovery. Patients were encouraged to perform a maximal exercise or stopped for dyspnea, exhaustion or ischemia. Peak exercise capacity was evaluated as metabolic equivalent METs and as peak double product (PDP) (Heart Rate $\times$ Systolic Blood pressure). Patients with inducible ischemia at perfusion imaging were excluded from this analysis to exclude this confounding factor.

Overall follow-up over a maximum of 5 years extended from baseline evaluation until last available contact. The following adverse events were recorded: hospitalization for heart failure, including new onset of heart failure, acute coronary syndrome, myocardial infarction, stroke, cardiovascular and total mortality. During follow-up, patients were monitored by their personal physicians. Events were ascertained by our database of medical records. 
Continuous variables are summarized as means $\pm \mathrm{SD}$. Categorical data are reported as numbers (percentage). Each echocardiographic and Doppler data point represents the average of 3 to 4 beats. The relationship between hemodynamic parameters, MR severity, and functional capacity (METs) was tested by linear regression. To identify potentially determinants of exercise capacity, all variables were submitted to a forward stepwise variable selection method. At each step, variables were entered until there was no significant improvement in the value of the $\mathrm{r}^{2}$. VC and MR jet area/LA area ratio were not used together since they are collinear. In the analysis of determinants of exercise capacity, LVEF was entered as a continuous variable and alternatively stratified as a categorical variable, with patients categorized into 3 groups: those with severe $\mathrm{LV}$ dysfunction (EF $\leq 35 \%$ ), mild to moderate LV dysfunction (EF between 36 and 49\%), and normal LV function or mild LV dysfunction (EF $250 \%$ ). Cox proportional hazards analysis was used to assess whether MR predicted events (Hospitalization for heart failure, acute coronary syndrome, myocardial infarction, stroke and cardiovascular and total mortality): we also used correlation analysis by Pearson's method to evaluate the relationship between demographic and clinical parameters, LV geometry and function, MR severity, and functional capacity (METs and PDP). Univariate and multivariate analysis of time to events was performed using Cox proportional hazards multivariate models with $\mathrm{VC}$ as an independent variable in continuous and categorical format with a cut - off value of $2 \mathrm{~mm}$, including lower cut-off values for patients with ischemic MR than for those with normal LV function. The $2 \mathrm{~mm}$ cut - off was chosen because it was the median value of the VC distribution in this study. For multivariable analyses of events, we used predefined Cox proportional hazards multivariable models that included covariates considered of potential prognostic impact (age, LVEDV, LVEF, and VC $>2 \mathrm{~mm}$ ). A value of $\mathrm{p}<0.05$ was considered significant. Data were analyzed with SAS 9.1 statistical software (SAS institute, Cary, NC).

\section{Results}

The eligibility criteria were fulfilled by 77 patients, mean age 64 years \pm 11 years, 59 men (77\%). Twelve (15\%) patients had atrial fibrillation. Mean EF was $54 \pm 11 \%$ (Table 1). Mean LV end-diastolic volume was $110 \pm 37 \mathrm{ml}$ (from 44.5 to $233 \mathrm{ml}$ ) and mean LV endsystolic volume was $51 \pm 23 \mathrm{ml}$ (from 15 to $130 \mathrm{ml}$ ). Six (7.8\%) patients had $\mathrm{EF} \leq 35 \%, 18$ (23\%) had EF between 36 and $49 \%$. Mean MR was mild to moderate with mean $\mathrm{VC}=2.0 \pm$ $1.4 \mathrm{~mm}$ and MR jet area / LA area ratio $=15 \pm 13 \%$. Heart rate and systolic blood pressure increased from rest to peak exercise ( $65 \pm 11$ vs. $124 \pm 25$ bpm, $123 \pm 22$ vs. $155 \pm 27$ $\mathrm{mmHg}$ ). Mean duration of exercise was $426 \pm 185 \mathrm{sec}$, and mean METs were 8.1 \pm 3.2. Other echocardiographic and stress test characteristics are shown in table 1. Mean overall duration of follow up was $29.5 \pm 13.0$ months (from 9 to 61 months). Ten events were recorded including 5 deaths ( 4 cardiac deaths).

MR quantification ( $\mathrm{p}<0.001)$ and LV end-diastolic volume $(\mathrm{p}=0.03)$ were significantly correlated with METs when EF was used as a categorical variable (severe, moderately, or mildly reduced, as categorized in the Methods section). Stepwise multiple linear regression analysis identified MR with VC ( $\beta$ coefficient $=-18.014, \mathrm{SE}=2.336, \mathrm{p}<0.0001)$ and $\mathrm{LV}$ end-diastolic volume $(\beta$ coefficient $=0.132 \mathrm{SE}=0.052, \mathrm{p}=0.015)$ as independent determinants of reduced functional capacity evaluated by METs. This effect of VC was present both as a categorical variable ( $>2 \mathrm{~mm}$ ) and as a continuous variable in the regression model. Univariate regression identified MR with both VC $(r=-0.674, \mathrm{p}<0.0001)$ (Figure 2) and MR jet area $(\mathrm{r}=-0.575, \mathrm{p}<0.0001)$ as determinants of reduced functional capacity evaluated by METs, with VC the stronger predictor. Tenting area showed a trend toward significance $(\mathrm{p}=0.053)$. There was no difference in the relation between decrease in METs and increase in VC in the patient groups with LVEF mildly, moderately, or severely impaired. 
LV end-diastolic and LV end-systolic diameters were inversely significantly correlated with exercise capacity evaluated by PDP $(\mathrm{r}=-0.315, \mathrm{p}=0.005$ and $\mathrm{r}=-0.27, \mathrm{p}=0.016$ respectively for LV end-diastolic and end-systolic diameters). There was no correlation when METs were used (Table 2). There was a significant correlation between age, male gender, atrial fibrillation, changes in HR, E/e' lateral, averaged E/e', tenting area, RVSP, WMSi with exercise capacity evaluated by METs. E deceleration time was also correlated with RVSP $(\mathrm{r}=-0.308, \mathrm{p}=0.008)$.

Combined CV morbidity and total mortality were significantly higher for patients with VC > $2 \mathrm{~mm}$ (HR 8.22, $\mathrm{p}=0.04)$, the only other significant factor was age (HR $0.92, \mathrm{p}=0.04$ ) (Figure 3, Table 3). Age was also a significant factor of morbidity (HR $0.75, \mathrm{p}=0.04$ ). There was no additional significant contribution to the model from other potential predictors. For $\mathrm{CV}$ morbidity and $\mathrm{CV}$ deaths, $\mathrm{VC}>2 \mathrm{~mm}$ had a $\mathrm{p}$ value of 0.06 and age a value of 0.055 .

\section{Discussion}

The main finding of this study is that ischemic MR negatively impacts exercise capacity and is associated with increased cardiovascular morbidity and mortality, in patients with inferior myocardial infarctions with wall motion abnormality. 1) Severity of ischemic MR in patients with inferior wall abnormalities and preserved LV ejection fraction in most cases correlate with decreased exercise capacity in the absence of active myocardial ischemia. 2) Severity of ischemic MR seems to be associated with a dismal prognosis in this context. 3) The impact of ischemic MR on exercise capacity seems to be independent from LV remodeling. Prior studies have suggested the prognostic value of exercise-induced MR for cardiovascular events ${ }^{19-22}$ because ischemic MR is more common and more severe with exercise than at rest $20,22,23$ and it is well - known that ischemic MR negatively affects myocardial contractility and LV remodeling. Additionally, the dynamics of mitral lesions with exercise have correlated better with functional outcomes than a resting evaluation. This study supports an impact of resting MR on exercise capacity with an implication that ischemic MR is not just an epiphenomenon of but a contributor to the ischemic remodeling process. In addition, the negative effect on exercise capacity is based on MR on a resting echocardiogram. Ennezat et al. studied a population with LV systolic dysfunction with an average LVEF of $26 \%$ and functional MR in which exercise MR did not add additional prognostic information in comparison with resting conventional echocardiography in patients with LV systolic dysfunction and functional MR ${ }^{24}$.

Both measures of MR used - VC and MR color jet area / LA area ratio - predicted the limitation on exercise capacity, although $\mathrm{VC}$, the more direct measure of the regurgitant orifice, was the more powerful predictive measure. This may relate to the more indirect nature of the color Doppler jet area, which overestimates functional MR severity ${ }^{25}$ and is influenced by the mechanism of MR ${ }^{26}$, left atrial size ${ }^{27}$, jet flow ${ }^{28}$, gain settings and pulse repetition frequency ${ }^{29}$, in contrast to $\mathrm{VC}$, which is considered a more robust measure reflecting the regurgitant orifice size most directly.

LVED volume was also a predictor of decreased functional capacity. Myocardial infarction, with loss of contracting myocytes leads to a sequence of events aimed at preserving cardiac output, including increased LV end-diastolic volume to augment preload. Cells in noninfarcted areas hypertrophy because of addition of contractile elements in series, creating eccentric hypertrophy without increased wall thickness. This allows the LV to dilate. Volume and pressure overload increase wall stress, which can aggravate remodeling ${ }^{30}$. Mitral regurgitation, caused by these alterations in ventricular geometry and function after MI can itself initiate the remodeling by activating the cellular and molecular remodeling 
process and also alter the overload on LV. By increasing diastolic wall stress and overload, it also contributes to LV dilatation ${ }^{31}$.

One potential mechanism for reduced exercise capacity is that ischemic MR decreases coronary flow reserve because of elevation of resting flow velocity, due to increased LV preload. A previous study has shown improvement of coronary flow reserve after MR repair because of reduction of LV preload and LV volume ${ }^{32}$.

In our study, averaged E/e', E deceleration time and RVSP correlated with exercise capacity. Exercise capacity depends on the backup of pressure into the LA and pulmonary circulation, which should depend upon the severity of MR in combination with diastolic filling properties. Other studies have demonstrated a correlation of E/e' to exercise capacity ${ }^{12}$. The association between METs and LV function is captured in the multivariate analysis by the relation between functional capacity and LV volume. LVEF may drop out of the model in part because as the severity of MR increases, any reduction in EF is masked by the need for the ventricle to compensate (higher EF) in order to sustain cardiac output.

MR jet area can be subject to loading conditions and machine settings and may underestimate MR, especially for eccentrically directed jets. The jets in these patients were central. All patients were stable outpatients and relatively stable loading conditions.

Variability in machine settings are minimized as echocardiograms were performed using a standard protocol with defined criteria for machine settings. In addition, our basic approach for MR quantification was $\mathrm{VC}$, with care to angulate the transducer and expand the region of interest to maximize visualization and quantification precision. We did not use Region of Interest (ROA) by PISA (Proximal Isovelocity Surface Area) to quantitate MR. VC has been validated and is a measure that is simple, reproducible, and not subject to changes in load compared to ROA by PISA or jet area. This is a retrospective study and therefore subjected to selection bias. But ischemic MR with wall motion abnormality patients selected based on our understanding of mechanisms of ischemic MR to select a homogeneous population to examine this question. The use of patients with inferior wall motion abnormalities allows building a homogenous group of patients with an important proportion of them having preserved LV EF, and a substantial number of patients without significant LV remodeling (Mean LV EDV $110 \mathrm{~mL}$ ). However, these results do not directly apply to the wide spectrum of patients with CAD, ischemic MR and extensive LV remodeling. Hence, the clinical implications, the rationale and the conclusions based on patients with CAD should focus on the present study population, that is patients without significant LV remodeling, allowing demonstrating at best the role of the severity of ischemic MR per se in the impairment of exercise capacity in patients with CAD.

\section{References}

1. Gibbons RJ, Balady GJ, Bricker JT, Chaitman BR, Fletcher GF, Froelicher VF, Mark DB, McCallister BD, Mooss AN, O'Reilly MG, Winters WL Jr, Gibbons RJ, Antman EM, Alpert JS, Faxon DP, Fuster V, Gregoratos G, Hiratzka LF, Jacobs AK, Russell RO, Smith SC Jr. ACC/AHA 2002 guideline update for exercise testing: summary article: a report of the American College of Cardiology/American Heart Association Task Force on Practice Guidelines (Committee to Update the 1997 Exercise Testing Guidelines). Circulation. 2002; 106:1883-1892. [PubMed: 12356646]

2. Navare SM, Mather JF, Shaw LJ, Fowler MS, Heller GV. Comparison of risk stratification with pharmacologic and exercise stress myocardial perfusion imaging: a meta-analysis. J Nucl Cardiol. 2004; 11:551-561. [PubMed: 15472640]

3. Myers J, Prakash M, Froelicher V, Do D, Partington S, Atwood JE. Exercise capacity and mortality among men referred for exercise testing. N Engl J Med. 2002; 346:793-801. [PubMed: 11893790] 
4. Goraya TY, Jacobsen SJ, Pellikka PA, Miller TD, Khan A, Weston SA, Gersh BJ, Roger VL. Prognostic value of treadmill exercise testing in elderly persons. Ann Intern Med. 2000; 132:862870. [PubMed: 10836912]

5. Spin JM, Prakash M, Froelicher VF, Partington S, Marcus R, Do D, Myers J. The prognostic value of exercise testing in elderly men. Am J Med. 2002; 112:453-459. [PubMed: 11959055]

6. Bonow RO, Carabello BA, Chatterjee K, de Leon AC Jr, Faxon DP, Freed MD, Gaasch WH, Lytle BW, Nishimura RA, O'Gara PT, O'Rourke RA, Otto CM, Shah PM, Shanewise JS, Smith SC Jr, Jacobs AK, Adams CD, Anderson JL, Antman EM, Fuster V, Halperin JL, Hiratzka LF, Hunt SA, Lytle BW, Nishimura R, Page RL, Riegel B. ACC/AHA 2006 guidelines for the management of patients with valvular heart disease: a report of the American College of Cardiology/American Heart Association Task Force on Practice Guidelines (writing Committee to Revise the 1998 guidelines for the management of patients with valvular heart disease) developed in collaboration with the Society of Cardiovascular Anesthesiologists endorsed by the Society for Cardiovascular Angiography and Interventions and the Society of Thoracic Surgeons. J Am Coll Cardiol. 2006; 48:e1-148. [PubMed: 16875962]

7. Kumanohoso T, Otsuji Y, Yoshifuku S, Matsukida K, Koriyama C, Kisanuki A, Minagoe S, Levine RA, Tei C. Mechanism of higher incidence of ischemic mitral regurgitation in patients with inferior myocardial infarction: quantitative analysis of left ventricular and mitral valve geometry in 103 patients with prior myocardial infarction. J Thorac Cardiovasc Surg. 2003; 125:135-143. [PubMed: 12538997]

8. Schiller NB, Shah PM, Crawford M, DeMaria A, Devereux R, Feigenbaum H, Gutgesell H, Reichek N, Sahn D, Schnittger I, et al. Recommendations for quantitation of the left ventricle by twodimensional echocardiography. American Society of Echocardiography Committee on Standards, Subcommittee on Quantitation of Two-Dimensional Echocardiograms. J Am Soc Echocardiogr. 1989; 2:358-367. [PubMed: 2698218]

9. Lancellotti P, Moura L, Pierard LA, Agricola E, Popescu BA, Tribouilloy C, Hagendorff A, Monin JL, Badano L, Zamorano JL. European Association of Echocardiography recommendations for the assessment of valvular regurgitation. Part 2: mitral and tricuspid regurgitation (native valve disease). Eur J Echocardiogr. 2010(11):307-332.

10. Ren JF, Kotler MN, DePace NL, Mintz GS, Kimbiris D, Kalman P, Ross J. Two-dimensional echocardiographic determination of left atrial emptying volume: a noninvasive index in quantifying the degree of nonrheumatic mitral regurgitation. J Am Coll Cardiol. 1983; 2:729-736. [PubMed: 6886234]

11. Ommen SR, Nishimura RA, Appleton CP, Miller FA, Oh JK, Redfield MM, Tajik AJ. Clinical utility of Doppler echocardiography and tissue Doppler imaging in the estimation of left ventricular filling pressures: A comparative simultaneous Doppler-catheterization study. Circulation. 2000; 102:1788-1804. [PubMed: 11023933]

12. Donal E, Raud-Raynier P, De Place C, Gervais R, Rosier A, Roulaud M, Ingels A, Carre F, Daubert JC, Denjean A. Resting echocardiographic assessments of left atrial function and filling pressure interest in the understanding of exercise capacity in patients with chronic congestive heart failure. J Am Soc Echocardiogr. 2008; 21:703-710. [PubMed: 18187295]

13. Hall SA, Brickner ME, Willett DL, Irani WN, Afridi I, Grayburn PA. Assessment of mitral regurgitation severity by Doppler color flow mapping of the vena contracta. Circulation. 1997; 95:636-642. [PubMed: 9024151]

14. Tribouilloy C, Shen WF, Quere JP, Rey JL, Choquet D, Dufosse H, Lesbre JP. Assessment of severity of mitral regurgitation by measuring regurgitant jet width at its origin with transesophageal Doppler color flow imaging. Circulation. 1992; 85:1248-1253. [PubMed: 1555268]

15. Helmcke F, Nanda NC, Hsiung MC, Soto B, Adey CK, Goyal RG, Gatewood RP Jr. Color Doppler assessment of mitral regurgitation with orthogonal planes. Circulation. 1987; 75:175-183. [PubMed: 3791603]

16. Zoghbi WA, Enriquez-Sarano M, Foster E, Grayburn PA, Kraft CD, Levine RA, Nihoyannopoulos P, Otto CM, Quinones MA, Rakowski H, Stewart WJ, Waggoner A, Weissman NJ. Recommendations for evaluation of the severity of native valvular regurgitation with two- 
dimensional and Doppler echocardiography. J Am Soc Echocardiogr. 2003; 16:777-802. [PubMed: 12835667]

17. Mele D, Vandervoort P, Palacios I, Rivera JM, Dinsmore RE, Schwammenthal E, Marshall JE, Weyman AE, Levine RA. Proximal jet size by Doppler color flow mapping predicts severity of mitral regurgitation. Clinical studies. Circulation. 1995; 91:746-754. [PubMed: 7828303]

18. Lang RM, Bierig M, Devereux RB, Flachskampf FA, Foster E, Pellikka PA, Picard MH, Roman MJ, Seward J, Shanewise JS, Solomon SD, Spencer KT, Sutton MS, Stewart WJ.

Recommendations for chamber quantification: a report from the American Society of Echocardiography's Guidelines and Standards Committee and the Chamber Quantification Writing Group, developed in conjunction with the European Association of Echocardiography, a branch of the European Society of Cardiology. J Am Soc Echocardiogr. 2005; 18:1440-1463. [PubMed: 16376782]

19. Lancellotti P, Troisfontaines P, Toussaint AC, Pierard LA. Prognostic importance of exerciseinduced changes in mitral regurgitation in patients with chronic ischemic left ventricular dysfunction. Circulation. 2003; 108:1713-1717. [PubMed: 12975251]

20. Kizilbash AM, Willett DL, Brickner ME, Heinle SK, Grayburn PA. Effects of afterload reduction on vena contracta width in mitral regurgitation. J Am Coll Cardiol. 1998; 32:427-431. [PubMed: 9708471]

21. Pierard LA, Lancellotti P. The role of ischemic mitral regurgitation in the pathogenesis of acute pulmonary edema. N Engl J Med. 2004; 351:1627-1634. [PubMed: 15483281]

22. Lapu-Bula R, Robert A, Van Craeynest D, D'Hondt AM, Gerber BL, Pasquet A, Melin JA, De Kock M, Vanoverschelde JL. Contribution of exercise-induced mitral regurgitation to exercise stroke volume and exercise capacity in patients with left ventricular systolic dysfunction. Circulation. 2002; 106:1342-1348. [PubMed: 12221050]

23. Lebrun F, Lancellotti P, Pierard LA. Quantitation of functional mitral regurgitation during bicycle exercise in patients with heart failure. J Am Coll Cardiol. 2001; 38:1685-1692. [PubMed: 11704381]

24. Ennezat PV, Marechaux S, Huerre C, Deklunder G, Asseman P, Jude B, Van Belle E, Mouquet F, Bauters C, Lamblin N, Lejemtel TH, de Groote P. Exercise does not enhance the prognostic value of Doppler echocardiography in patients with left ventricular systolic dysfunction and functional mitral regurgitation at rest. Am Heart J. 2008; 155:752-757. [PubMed: 18371488]

25. McCully RB, Enriquez-Sarano M, Tajik AJ, Seward JB. Overestimation of severity of ischemic/ functional mitral regurgitation by color Doppler jet area. Am J Cardiol. 1994; 74:790-793. [PubMed: 7942551]

26. Enriquez-Sarano M, Tajik AJ, Bailey KR, Seward JB. Color flow imaging compared with quantitative Doppler assessment of severity of mitral regurgitation: influence of eccentricity of jet and mechanism of regurgitation. J Am Coll Cardiol. 1993; 21:1211-1219. [PubMed: 8459079]

27. Maciel BC, Moises VA, Shandas R, Simpson IA, Beltran M, Valdes-Cruz L, Sahn DJ. Effects of pressure and volume of the receiving chamber on the spatial distribution of regurgitant jets as imaged by color Doppler flow mapping An in vitro study. Circulation. 1991; 83:605-613. [PubMed: 1991378]

28. Thomas JD, Liu CM, Flachskampf FA, O'Shea JP, Davidoff R, Weyman AE. Quantification of jet flow by momentum analysis. An in vitro color Doppler flow study. Circulation. 1990; 81:247-259. [PubMed: 2404625]

29. Hoit BD, Jones M, Eidbo EE, Elias W, Sahn DJ. Sources of variability for Doppler color flow mapping of regurgitant jets in an animal model of mitral regurgitation. J Am Coll Cardiol. 1989; 13:1631-1636. [PubMed: 2723277]

30. Sam F, Sawyer DB, Chang DL, Eberli FR, Ngoy S, Jain M, Amin J, Apstein CS, Colucci WS. Progressive left ventricular remodeling and apoptosis late after myocardial infarction in mouse heart. Am J Physiol Heart Circ Physiol. 2000; 279:H422-H428. [PubMed: 10899082]

31. Beeri R, Yosefy C, Guerrero JL, Nesta F, Abedat S, Chaput M, del Monte F, Handschumacher MD, Stroud R, Sullivan S, Pugatsch T, Gilon D, Vlahakes GJ, Spinale FG, Hajjar RJ, Levine RA. Mitral regurgitation augments post-myocardial infarction remodeling failure of hypertrophic compensation. J Am Coll Cardiol. 2008; 51:476-486. [PubMed: 18222360] 
32. Akasaka T, Yoshida K, Hozumi T, Takagi T, Kaji S, Kawamoto T, Ueda Y, Okada Y, Morioka S, Yoshikawa J. Restricted coronary flow reserve in patients with mitral regurgitation improves after mitral reconstructive surgery. J Am Coll Cardiol. 1998; 32:1923-1930. [PubMed: 9857873]

33. Tumminello G, Lancellotti P, Lempereur M, D'Orio V, Pierard LA. Determinants of pulmonary artery hypertension at rest and during exercise in patients with heart failure. Eur Heart J. 2007; 28:569-574. [PubMed: 17314112] 


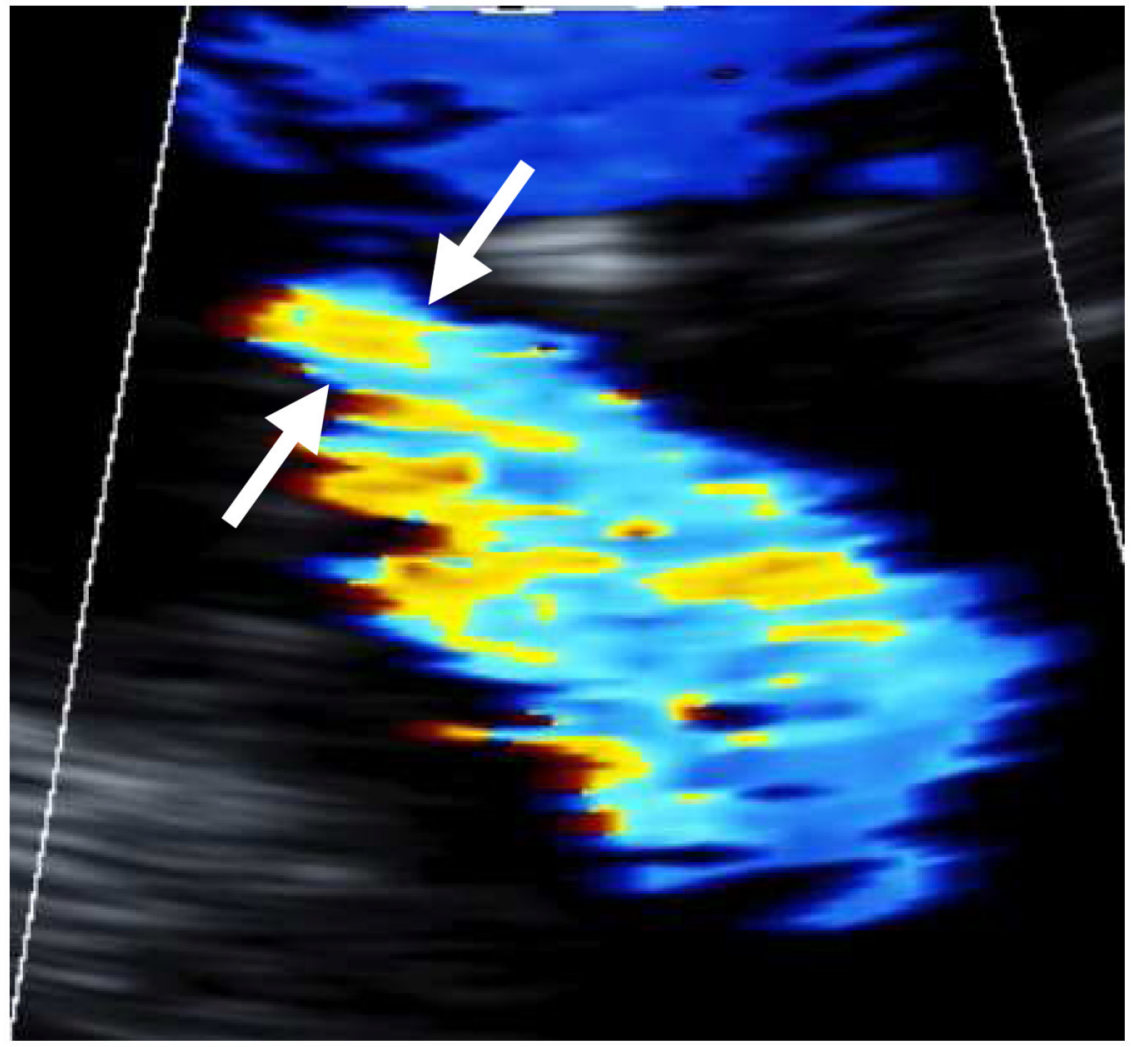

Figure 1.

Color Doppler showing vena contracta (VC) width in the parasternal long axis view. 
METS vs Vena Contracta

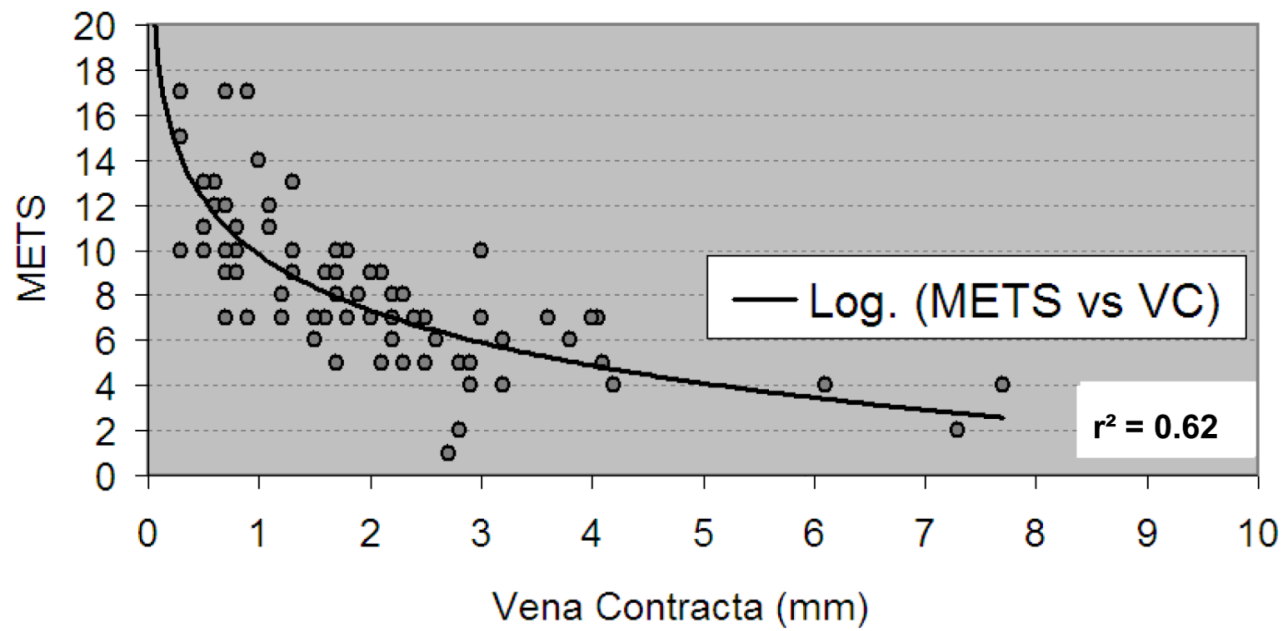

Figure 2.

Determinants of functional capacity (METS). Correlation between METS (y-axis) and mitral regurgitation (VC-vena contracta (x-axis)). 


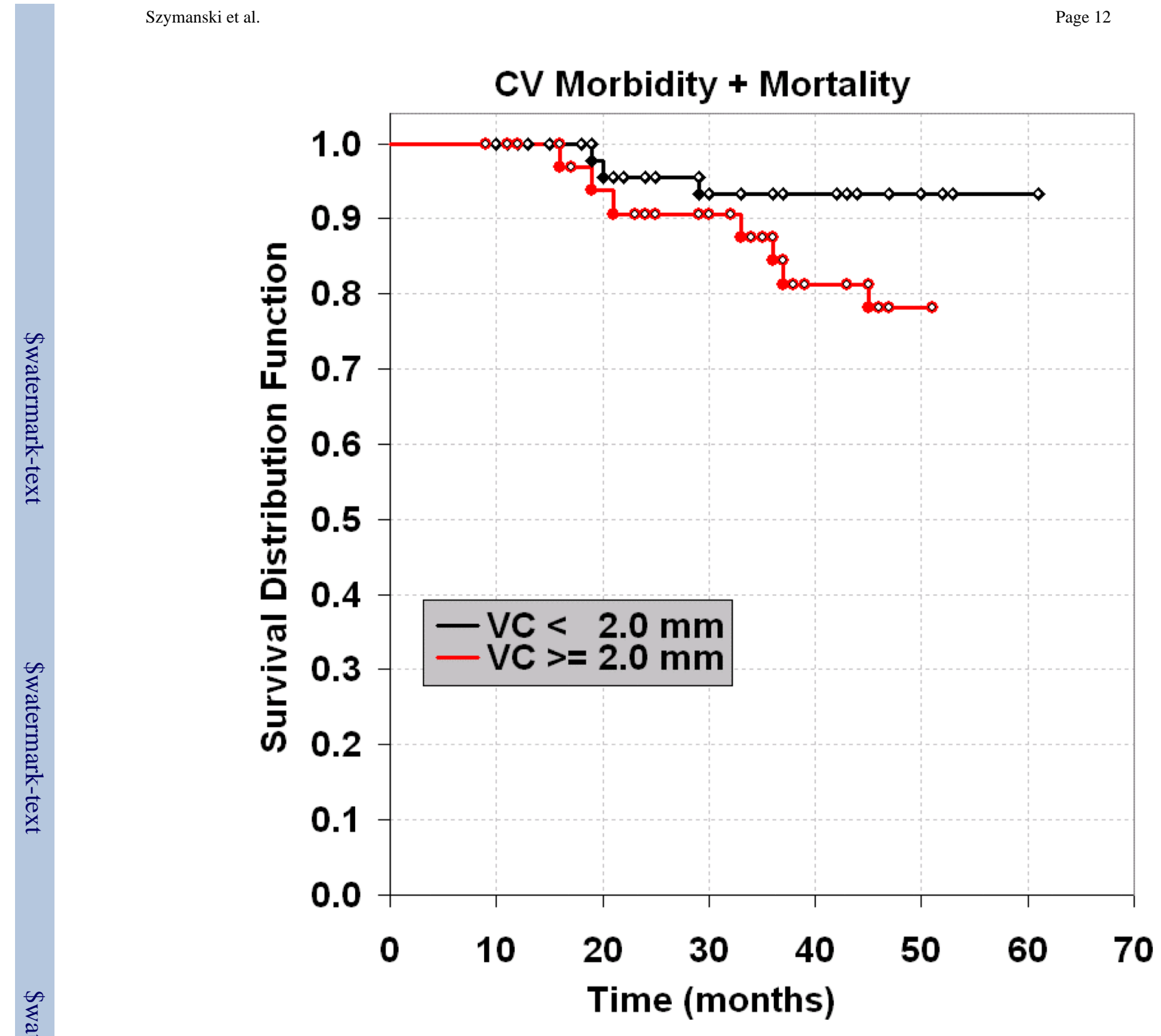

Figure 3.

Overall survival and $\mathrm{CV}$ morbidity according to $\mathrm{VC}$ in patients with ischemic MR. 
Table 1

Echocardiographic characteristics of patients in the whole 77-patient-population, and 2 subgroups relative to the occurrence of events.

\begin{tabular}{|c|c|c|c|c|}
\hline Parameters & $\begin{array}{l}\text { Mean } \pm \text { SD Total } \\
\text { population }(n=77)\end{array}$ & $\begin{array}{c}\text { Mean } \pm \text { SD Patients } \\
\text { without events }(n=67 \text {; } \\
87 \%)\end{array}$ & $\begin{array}{c}\text { Mean } \pm \text { SD Patients } \\
\text { with events }(n=10 ; \\
13 \%)\end{array}$ & p value \\
\hline Left ventricular end-diastolic volume (mL) & $110 \pm 37$ & $108 \pm 37$ & $119 \pm 41$ & 0.373 \\
\hline Left ventricular end-systolic volume (mL) & $51 \pm 23$ & $49 \pm 22$ & $61 \pm 28$ & 0.138 \\
\hline Left ventricular ejection fraction (\%) & $54 \pm 11$ & $55 \pm 11$ & $50 \pm 10$ & 0.215 \\
\hline Left ventricular end-diastolic diameter ( $\mathrm{mm})$ & $49 \pm 6$ & $49 \pm 5$ & $54 \pm 9$ & 0.013 \\
\hline Left ventricular end-systolicdiameter (mm) & $35 \pm 7$ & $34 \pm 6$ & $41 \pm 8$ & 0.004 \\
\hline Right ventricular systolic pressure $(\mathrm{mmHg})$ & $36 \pm 14$ & $34 \pm 12$ & $47 \pm 21$ & 0.011 \\
\hline Left atrial volume $(\mathrm{mL})$ & $70 \pm 27$ & $67 \pm 26$ & $89 \pm 44$ & 0.027 \\
\hline Tenting area $\left(\mathrm{mm}^{2}\right)$ & $0.73 \pm 0.42$ & $0.66 \pm 0.34$ & $1.20 \pm 0.60$ & $<0.0001$ \\
\hline $\mathrm{E} / \mathrm{e}^{\prime}$ lateral & $9 \pm 5$ & $8 \pm 3$ & $13 \pm 9$ & 0.003 \\
\hline E/e' septal & $7 \pm 2$ & $11 \pm 6$ & $12 \pm 5$ & 0.695 \\
\hline $\mathrm{E} /$ averaged $\mathrm{e}^{\prime}$ & $10 \pm 5$ & $10 \pm 5$ & $14 \pm 7$ & 0.019 \\
\hline E deceleration time (msec) & $232 \pm 75$ & $235 \pm 77$ & $209 \pm 60$ & 0.323 \\
\hline Wall motion score index (score) & $0.41 \pm 0.3$ & $0.40 \pm 0.3$ & $0.47 \pm 0.31$ & 0.537 \\
\hline Vena Contracta (mm) & $2 \pm 1.4$ & $1.8 \pm 1.3$ & $3.1 \pm 2.1$ & 0.08 \\
\hline Mitral regurgitation jet area / left atrial area ratio $(\%)$ & $15 \pm 13$ & $13 \pm 12$ & $23 \pm 19$ & 0.024 \\
\hline
\end{tabular}


Table 2

\section{Correlations with exercise capacity (METs and peak double product)}

\begin{tabular}{|c|c|c|c|c|}
\hline \multirow[t]{2}{*}{ Variables } & \multicolumn{2}{|c|}{ METs } & \multicolumn{2}{|c|}{ Peak double produc } \\
\hline & $\mathbf{r}$ & $\mathbf{p}$ & $\mathbf{r}$ & $\mathbf{p}$ \\
\hline \multicolumn{5}{|l|}{ Demographic data } \\
\hline Age & -0.255 & 0.025 & $-0,007$ & 0.955 \\
\hline Male gender & 0.293 & 0.010 & 0.040 & 0.727 \\
\hline \multicolumn{5}{|l|}{ Clinical Data } \\
\hline Beta blockers & 0.168 & 0.145 & $-0,030$ & 0.794 \\
\hline Atrial fibrillation & -0.343 & 0.002 & 0.099 & 0.392 \\
\hline Diabetes & -0.145 & 0.207 & -0.080 & 0.487 \\
\hline Smoking & -0.043 & 0.71 & 0.175 & 0.128 \\
\hline Hypertension & -0.081 & 0.486 & 0.030 & 0.794 \\
\hline Dyslipemia & 0.111 & 0.335 & -0.112 & 0.732 \\
\hline History of coronary artery disease & 0.233 & 0.042 & 0.151 & 0.190 \\
\hline Heart rhythm changes & 0.623 & $<0.001$ & 0.703 & $<0.001$ \\
\hline \multicolumn{5}{|l|}{ LV geometry and function } \\
\hline LV end-diastolic volume & 0.235 & 0.04 & -0.059 & 0.611 \\
\hline LV end-systolic volume & 0.070 & 0.542 & -0.162 & 0.160 \\
\hline LV ejection fraction & 0.159 & 0.703 & 0.233 & 0.041 \\
\hline LV end-diastolic diameter & 0.099 & 0.39 & -0.315 & 0.005 \\
\hline LV end-systolic diameter & -0.50 & 0.66 & -0.276 & 0.016 \\
\hline $\mathrm{E} / \mathrm{e}^{\prime}$ lateral & -0.352 & 0.003 & -0.280 & 0.019 \\
\hline $\mathrm{E} / \mathrm{e}^{\prime}$ medial & -0.221 & 0.062 & -0.024 & 0.843 \\
\hline $\mathrm{E} /$ averaged $\mathrm{e}^{\prime}$ & -0.341 & 0.003 & -0.232 & 0.048 \\
\hline E deceleration time & -0.313 & 0.006 & 0.160 & 0.166 \\
\hline Wall motion score index & -0.245 & 0.032 & -0.418 & $<0.001$ \\
\hline Sphericity index & -0.047 & 0.686 & 0.201 & 0.082 \\
\hline Rest cardiac output & 0.002 & 0.987 & 0.161 & 0.163 \\
\hline \multicolumn{5}{|l|}{ Mitral regurgitation severity } \\
\hline Vena contracta & -0.674 & $<0.001$ & -0.260 & 0.022 \\
\hline Mitral regurgitation jet area / left atrial area ratio & -0.575 & $<0.001$ & -0.223 & 0.052 \\
\hline
\end{tabular}




\begin{tabular}{lcccc}
\hline Variables & \multicolumn{2}{c}{ METs } & \multicolumn{2}{c}{ Peak double product } \\
& r & p & r & p \\
\hline Tenting area & -0.430 & $<0.001$ & -0.147 & 0.202 \\
Right ventricular systolic pressures & -0.424 & $<0.001$ & -0.253 & 0.031 \\
Left atrial volume & -0.168 & 0.143 & -0.074 & 0.520
\end{tabular}


Table 3

\section{Univariate and multivariate parameters included in the Cox PH model}

\begin{tabular}{lllll}
\hline Variables & Univariate HR & Univariate p value & Multivariate HR & Multivariate p value \\
\hline Age & $0.972[0.910-1.038]$ & 0.3947 & $0.926[0.8569-1.0014]$ & 0.0543 \\
Left ventricular end-diastolic volume & $1.004[0.991-1.018]$ & 0.5566 & $1.009[0.9932-1.0250]$ & 0.2648 \\
Ejection fraction & $0.969[0.921-1.02]$ & 0.2324 & $0.956[0.9017-1.0125]$ & 0.124 \\
Vena Contracta $>2 \mathrm{~mm}$ & $2.785[0.716-10.83]$ & 0.1393 & $7.43[1.4934-36.9622]$ & 0.0143 \\
\hline
\end{tabular}

